\title{
Distribution of left ventricular ejection fraction in angina patients with severe coronary artery disease not amenable to revascularization.
}

\author{
Shuchita Gupta \\ Einstein Institute for Heart and Vascular Health, Albert Einstein Medical Center \\ Gregg S. Pressman \\ Einstein Medical Center \\ D Lynn Morris \\ Einstein Institute for Heart and Vascular Health, Albert Einstein Medical Center \\ Vincent M. Figueredo, M.D. \\ Fbipowa thiletfertsodditiokerisittbrks at: https://jdc.jefferson.edu/cardiologyfp \\ Part of the Cardiology Commons

\section{Let us know how access to this document benefits you}

\section{Recommended Citation}

Gupta, Shuchita; Pressman, Gregg S.; Morris, D Lynn; and Figueredo, M.D., Vincent M., "Distribution of left ventricular ejection fraction in angina patients with severe coronary artery disease not amenable to revascularization." (2010). Division of Cardiology Faculty Papers. Paper 17.

https://jdc.jefferson.edu/cardiologyfp/17

This Article is brought to you for free and open access by the Jefferson Digital Commons. The Jefferson Digital Commons is a service of Thomas Jefferson University's Center for Teaching and Learning (CTL). The Commons is a showcase for Jefferson books and journals, peer-reviewed scholarly publications, unique historical collections from the University archives, and teaching tools. The Jefferson Digital Commons allows researchers and interested readers anywhere in the world to learn about and keep up to date with Jefferson scholarship. This article has been accepted for inclusion in Division of Cardiology Faculty Papers by an authorized administrator of the Jefferson Digital Commons. For more information, please contact: JeffersonDigitalCommons@jefferson.edu. 


\title{
As submitted to:
}

\author{
Coronary Artery Disease
}

And later published as:

Distribution of Left Ventricular Ejection Fraction in

Angina Patients with Severe Coronary Artery Disease

Not Amenable to Revascularization

Volume 21, Issue 5, August 2010, Pages 278-280

DOI: 10.1097/MCA.0b013e32833bdf53

Shuchita Gupta, MD, Gregg S. Pressman, MD, D. Lynn Morris, MD, and Vincent M.

Figueredo, MD

Einstein Institute for Heart and Vascular Health, Albert Einstein Medical Center, and Jefferson Medical College, Philadelphia, PA

Running Head: Left Ventricular Ejection Fraction in Non-Revascularizable Angina

Patients 
Key words: angina, coronary artery disease, left ventricular ejection fraction, cardiomyopathy, non-revascularizable

Disclosures: No conflicts of interest

Corresponding author: Vincent M. Figueredo, MD

Einstein Institute for Heart and Vascular Health

5501 Old York Road, Levy 3232

Philadelphia, PA 19141

Phone: 215-456-8991

Fax: 215-456-3533

Email: figueredov@einstein.edu 


\section{Abstract}

Background: As the number of angina patients with severe coronary artery disease (CAD) not amenable to revascularization increase, new therapies will be developed. How patients with depressed compared to normal left ventricular ejection fraction (LVEF) will respond to new therapies may differ.

Hypothesis: We conducted a retrospective chart review to determine the distribution of LVEF in angina patients with severe CAD (three vessel disease with $>50 \%$ stenosis major epicardial vessels or $>50 \%$ stenosis left main) not amenable to revascularization. Methods: Patients underwent cardiac catheterization between 2004 and 2009. LVEF, measured by echocardiography, nuclear-gated imaging or radioventriculography within six months of catheterization was recorded. Demographics, symptoms, risk factors, past myocardial infarction, catheterization results, medications, and Duke Coronary Artery Jeopardy Score were recorded.

Results: 8699 patient charts were reviewed; 124 met criteria. There was a continuous, and not bimodal, distribution of LVEF. Fifty-eight patients (47\%) in the normal LVEF group were compared to 66 patients $(53 \%)$ in the abnormal LVEF group $(<50 \%)$. The two groups were statistically different only with respect to shortness of breath as a presenting symptom and diagnosis of congestive heart failure (CHF) during index hospitalization. Follow-up mortality was high and did not differ between LVEF groups (35\% versus $34 \%)$.

Conclusions: There is a wide distribution of LVEF among angina patients not amenable to revascularization. A novel finding of this study showed mortality was high regardless 
of LVEF. As new therapies for angina are developed, attention will need to be paid to how such therapies affect these two patient groups. 
A subset of patients with angina have severe CAD which is not amenable to revascularization by percutaneous coronary intervention or coronary artery bypass surgery. These patients demonstrate diffuse triple vessel disease, sometimes involving the left main coronary artery. Their prognosis is poor ${ }^{1,2}$, and management is aimed primarily at relieving anginal symptoms and preventing further cardiovascular events. The classic anti-anginal medications used are nitrates, beta-blockers and calcium channel blockers. Recently, ranolazine was added to the anti-anginal armamentarium. Ranolazine is thought to work by reducing intra-myocyte calcium levels and improving myocardial relaxation $^{3.4}$. The effectiveness and tolerability of these drugs (as well as new classes of anti-anginal drugs) varies based on the patient's underlying left ventricular function. There is little information in the medical literature documenting LVEF in nonrevascularizable chronic angina patients ${ }^{5}$. Anecdotal data suggest a bimodal distribution, with one group maintaining a preserved LVEF and the other with a significantly depressed LVEF.

We conducted a retrospective chart review to determine the distribution of LVEF in patients with chronic stable angina with severe CAD not amenable to revascularization. Our hypothesis was that LVEF demonstrates a bimodal distribution in angina patients with severe coronary artery disease not amenable to revascularization. 
Methods:

Patients with angina and documented severe CAD (defined as three vessel disease with $>50 \%$ stenosis of the major epicardial vessels and/or $>50 \%$ involvement of the left main coronary artery) deemed unfit for revascularization by interventional cardiologists and cardiac surgeons were identified from retrospective chart review of patients undergoing cardiac catheterization at Albert Einstein Medical Center in Philadelphia, PA between 2004 and 2009. LVEF, measured by echocardiography, nuclear-gated imaging or radioventriculography within six months of the catheterization, was recorded. Exclusion criteria included acute myocardial infarction (MI) at the time of catheterization and severe valvular disease. Data regarding demographics, symptoms, risk factors for coronary artery disease, past history of myocardial infarction, results of cardiac catheterization, and medications prescribed on a chronic basis were recorded. An interventional cardiologist reviewed the index cardiac catheterization report for each patient to calculate the Duke's Coronary Artery Jeopardy Score (a score from 0 to 12 which estimates the amount of myocardium at risk on the basis of particular location of coronary stenoses $)^{6}$. This score was calculated for all patients except those with significant left main disease in whom the Jeopardy Score has not been validated. Mortality data was acquired for all patients using the Social Security Death Index records through January 2010.

LVEF's were divided by intervals of $10 \%$ and plotted against the number of patients in each group. Additionally, patients were divided in to two groups on the basis of LVEF: 1. 
normal LVEF: including patients with a LVEF $>=50 \%$ and 2. Abnormal LVEF: consisting of patients with a $\mathrm{LVEF}<50 \%$.

\begin{abstract}
All data was analyzed using STATA 10 software (StataCorp, College Station, TX). Differences between the two groups were analyzed using Fisher's exact t-test with respect to risk factors, clinical features, medications, and jeopardy scores. Multivariable logistic regression analysis was performed using the variables age, gender, history of hypertension, history of diabetes, history of prior myocardial infarction and the diagnosis of congestive heart failure (CHF).
\end{abstract}


Results:

A total of 8699 charts were reviewed retrospectively. Out of these, 124 patients met our criteria and were included in the study. The distribution of LVEF is shown in the figure. Patients were then divided into a normal LVEF group $(\mathrm{n}=58 ; 47 \%)$ and an abnormal LVEF group ( $\mathrm{n}=66 ; 53 \%)$. Characteristics of the two groups are presented in the table. There was no statistically significant difference between the two groups with respect to cardiac risk factors, medications prescribed and Duke Coronary Artery Jeopardy Score. The two groups were statistically different only with respect to shortness of breath as a presenting symptom and the diagnosis of congestive heart failure (CHF) during index hospitalization. A greater proportion of patients with normal LVEF had a body mass index greater than $35 \mathrm{~kg} / \mathrm{m}^{2}(\mathrm{n}=23,40 \%)$ than those with abnormal LVEF $(\mathrm{n}=15,23 \%)$, the difference trending towards statistical significance $(\mathrm{p}=0.052)$. Of note, none of the patients in either group was on ranolazine.

There were more subsequent admissions in those with an abnormal LVEF, primarily due to $\mathrm{CHF}$ exacerbations. Mortality was similar, and high, in both LVEF groups $(35 \%$ in normal LVEF as compared to $34 \%$ in abnormal LVEF group, $\mathrm{p}=0.323$ ).

Multivariate logistic regression analysis using the variables age, gender, history of hypertension, diabetes, prior myocardial infarction and the diagnosis of $\mathrm{CHF}$, revealed $\mathrm{CHF}$ alone as a significantly different factor between the two groups $(\mathrm{p}<0.001)$. 


\section{Discussion:}

We conducted a retrospective chart review to determine the distribution of LVEF in patients with angina and severe CAD not amenable to revascularization. Our hypothesis was that LVEF demonstrates a bimodal distribution in patients with severe coronary artery disease not amenable to revascularization. We found that LVEF was widely distributed and did not follow a bimodal distribution. Of note, approximately half of patients had an LVEF greater than $50 \%$ and half less than $50 \%$. There was no statistically significant difference between these two groups with respect to cardiac risk factors, medications prescribed or Duke Coronary Artery Jeopardy Score. The two groups were statistically different only with respect to shortness of breath as a presenting symptom and the diagnosis of congestive heart failure (CHF) during index hospitalization. Multivariate logistic regression analysis revealed that a diagnosis of $\mathrm{CHF}$ on index hospitalization alone was a significantly different factor between the two groups. A novel finding of this study was the high follow-up mortality that was independent of LVEF.

Treatment options for symptom relief are limited for the growing number of chronic angina patients with severe coronary artery disease, not amenable to revascularization. Pharmacological medical therapy remains the mainstay for symptom control in these patients. There is inconclusive data supporting the use of nonconventional interventions such as spinal cord stimulation, upper thoracic sympathectomy, high thoracic epidural analgesia, chronic-intermittent urokinase administration, enhanced external counterpulsation and transmyocardial laser revascularization ${ }^{7}$. 
Pharmacological therapy for the treatment of angina began with the introduction of nitrates in $1867^{8}$. Beta-blockers were introduced in 1962. Calcium channel blockers became available in 1981. For those patients not responsive to pharmacological therapy, coronary artery bypass grafting became available in 1967 and percutaneous coronary intervention in $1977^{9}$.

For those patients with severe coronary artery disease who were not amenable to myocardial revascularization techniques, pharmacological treatment options were limited to drug classes introduced over 25 years ago. Ranolazine, a new class of anti-anginal drug, is thought to work by reducing intra-myocyte calcium levels and improving myocardial relaxation. The effectiveness and tolerability of this drug (as well as new classes of anti-anginal drugs) may vary based on the patient's underlying left ventricular function ${ }^{10}$.

As the number of angina patients with severe coronary artery disease not amenable to revascularization increase, new therapies will be introduced. How patients with depressed compared to normal LVEF respond to this new therapies, such as ranolazine is not known. Our study demonstrates there is a wide distribution of LVEF among chronic angina patients not amenable to revascularization. These patients have a high mortality irrespective of LVEF. As new therapies for angina are developed, attention to how such therapies affect these patient groups will require study. 


\section{References:}

1. Dubettier S, Milon H, de Gevigney G, Garé JP, Delahaye JP. Prognosis of nonrevascularized triple coronary vessel disease. Apropos of 87 cases. Arch Mal Coeur Vaiss. 1994 Sep;87(9):1177-83.

2. Yabe T, Takata J, Chikamori T, Seo H, Yamada M, Yamasaki F, Doi Y. Prognosis of patients with triple vessel disease and old myocardial infarction: relationship to the number of total coronary occlusions. J Cardiol. 1995 Nov;26(5):281-6.

3. Hasenfuss G, Maier LS. Mechanism of action of the new anti-ischemia drug ranolazine. Clin Res Cardiol. 2008 Apr;97(4):222-6.

4. Maier LS. A novel mechanism for the treatment of angina, arrhythmias, and diastolic dysfunction: inhibition of late $\mathrm{I}(\mathrm{Na})$ using ranolazine. J Cardiovasc Pharmacol. 2009 Oct;54(4):279-86.

5. Nishiyama S, Iwase T, Nishi Y, Ishiwata S, Komiyama N, Yanagishita Y, Nakanishi S, Seki A. Long-term outcome in triple-vessel coronary artery disease in medically treated Japanese patients. Jpn Heart J. 1998 Jan;39(1):67-77. Jpn Heart J. 1998 Jan;39(1):67-77.

6. Califf RM, Phillips HR III, Hindman MC, et al. Prognostic value of a coronary artery jeopardy score. J Am Coll Cardiol. 1985;5:1055-63.

7. Kim MC, Kini A, Sharma SK. Refractory angina pectoris: mechanism and therapeutic options. J Am Coll Cardiol. 2002 Mar 20;39(6):923-34.

8. Murrell W. Nitroglycerine as a remedy for angina pectoris. Lancet 1879;1:80-1, $113-5,151-2,225-7$. 
9. Boden WE, O'Rourke RA, Teo KK, Hartigan PM, Maron DJ, Kostuk WJ. Optimal medical therapy with or without PCI for stable coronary disease. $N$ Engl J Med. Apr 12 2007;356(15):1503-16.

10. Nash DT, Nash SD. Ranolazine for chronic stable angina. Lancet. 2008 Oct 11;372(9646):1335-41. 
Table 1. Characteristics of the two patient groups

\begin{tabular}{|c|c|c|c|}
\hline Characteristic & $\begin{array}{l}\text { Normal } \\
\text { LVEF } \\
(\mathrm{n}=58)\end{array}$ & $\begin{array}{l}\text { Abnormal } \\
\text { LVEF } \\
(n=66)\end{array}$ & $\mathrm{P}$ value \\
\hline Age (mean \pm SD) & $70.2 \pm 10.5$ & $71.4 \pm 11.5$ & 0.547 \\
\hline \multicolumn{4}{|l|}{ Sex } \\
\hline Male & 32 & 42 & 0.364 \\
\hline Female & 26 & 24 & \\
\hline Hypertension & 48 & 48 & 0.203 \\
\hline Diabetes & 32 & 36 & 0.544 \\
\hline Dyslipidemia & 38 & 35 & 0.201 \\
\hline Obesity (BMI>35 kg/m2) & 23 & 15 & 0.052 \\
\hline History of smoking & 28 & 39 & 0.279 \\
\hline Past history of myocardial infarction & 22 & 30 & 0.467 \\
\hline Family history of premature CAD & 19 & 26 & 0.461 \\
\hline Dyspnea as a presenting complaint & 18 & 54 & $<0.001$ \\
\hline CHF & 7 & 48 & $<0.001$ \\
\hline Arrhythmias & 11 & 22 & 0.103 \\
\hline \multicolumn{4}{|l|}{ Medications } \\
\hline Aspirin & 45 & 47 & 0.134 \\
\hline Plavix & 16 & 19 & 0.539 \\
\hline
\end{tabular}




\begin{tabular}{|c|l|l|l|}
\hline Beta-blocker & 18 & 17 & 0.422 \\
Calcium channel blocker & 19 & 19 & 0.555 \\
ACE-inhibitor/ ARB & 31 & 34 & 0.583 \\
Statin & 40 & 40 & 0.173 \\
Diuretic & 18 & 26 & 0.569 \\
\hline Subsequent admissions for cardiac complications & 100 & 131 & $<0.001$ \\
Admissions for angina & 79 & 66 & \\
Admissions for congestive heart failure & 21 & 65 & \\
& & & \\
\hline Duke's jeopardy score (mean) & 8.8 & 9.4 & 0.150 \\
\hline Mortality & 35 & 34 & 0.323 \\
\hline
\end{tabular}


Figure Legend: Distribution of left ventricular ejection fraction (LVEF) in angina patients with severe coronary artery disease not amenable to myocardial revascularization $(n=124)$.

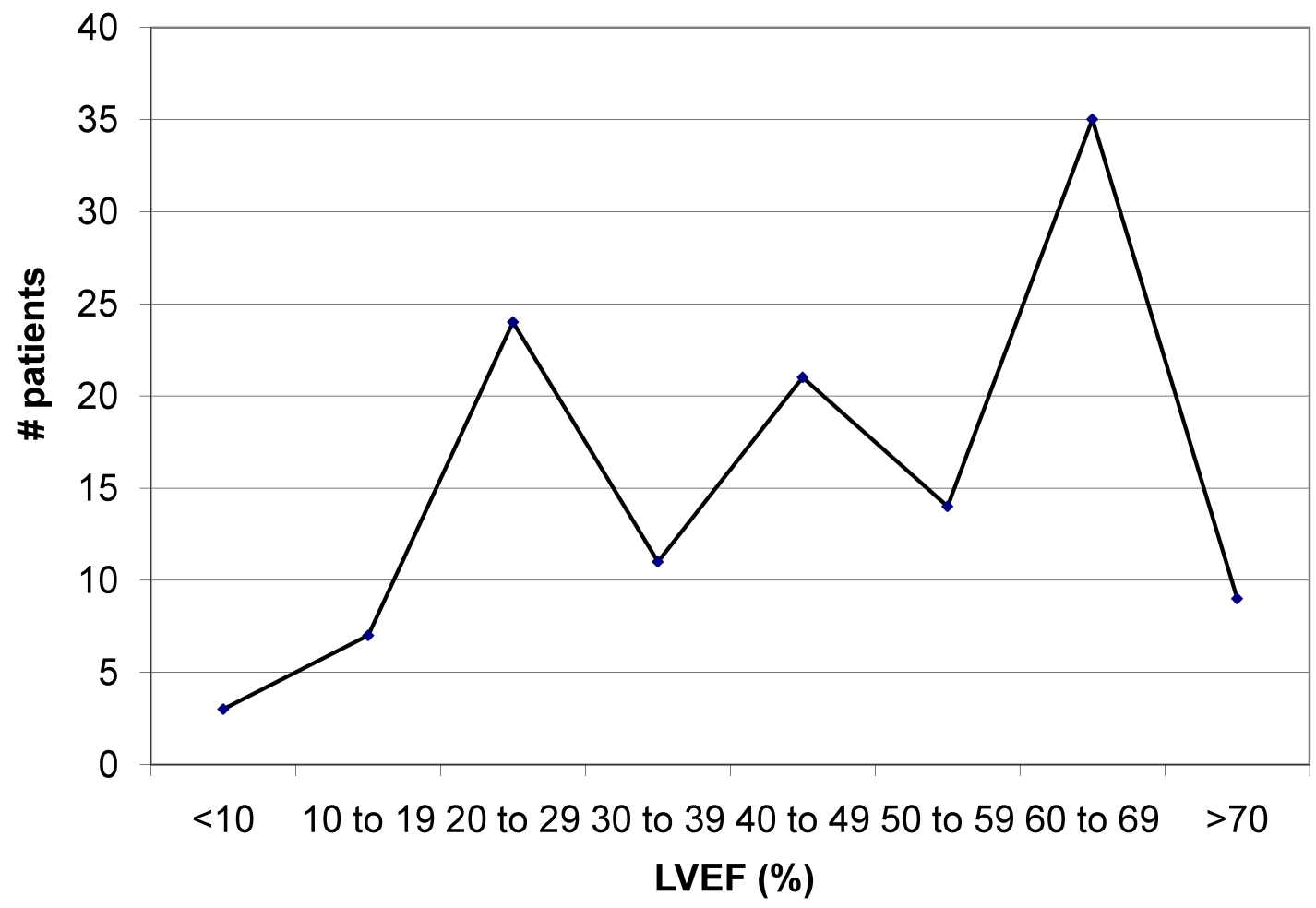

